\title{
Malaise, CTCAE
}

National Cancer Institute

\section{Source}

National Cancer Institute. Malaise, CT CAE. NCI Thesaurus. Code C143665.

A disorder characterized by a feeling of general discomfort or uneasiness, an out-ofsorts feeling. 